\title{
Luminescence studies in swift heavy ion irradiated aluminum silicates
}

\author{
B.N. Lakshminarasappa ${ }^{a, *}$, H. Nagabhushana ${ }^{a}$, Fouran Singh ${ }^{b}$ \\ ${ }^{a}$ Department of Physics, Jnana Bharathi Campus, Bangalore University, Bangalore 560 056, India \\ b Material Science Division, Nuclear Science Centre, Aruna Asaf Ali Marg, New Delhi 110 067, India
}

Available online 24 January 2006

\begin{abstract}
Thermoluminescence (TL) of kyanite single crystals bombarded with $100 \mathrm{MeV}$ swift $\mathrm{Ag}^{8+}$ and $\mathrm{Si}^{8+}$ ions with fluences in the range $1 \times 10^{11}-5 \times 10^{14}$ ions/ $\mathrm{cm}^{2}$ has been studied at room temperature (RT). Two TL glows with peaks one at $\sim 445 \mathrm{~K}$ and another one at $\sim 550 \mathrm{~K}$ are recorded in $\mathrm{Si}^{8+}$ ion bombarded kyanite single crystals at a warming rate of $20 \mathrm{~K} \mathrm{~min}{ }^{-1}$. It is observed that the TL peak intensity increases with increase of ion fluence. This may be attributed to the creation of new traps during bombardment process. However, in the case of $\mathrm{Ag}^{8+}$ ion bombarded samples, a single well resolved glow with peak at $\sim 520 \mathrm{~K}$ is observed in all the samples. Also, photoluminescence (PL) of $\mathrm{Ag}^{8+}$ ion irradiated kyanite single crystals have been studied and it is observed that a pair of sharp as well as strong PL emission bands with peaks at $\sim 688$ and $706 \mathrm{~nm}$ along with a broad emission band in the region $710-800 \mathrm{~nm}$ at an excitation of $442 \mathrm{~nm}$ laser beam. It is found that PL intensity decreases with increase of ion fluence. The decrease in intensity with increase of ion fluence is attributed to amorphization of the sample.
\end{abstract}

(C) 2005 Elsevier B.V. All rights reserved.

PACS: 61.72.Ji; 32.50.F; 81.20

Keywords: Thermoluminescence; Photoluminescence; Amorphization; Heavy ion

\section{Introduction}

The search of materials suitable for solid state radiation dosimeters has become the main aim of many researchers after the discovery of thermoluminescence phenomena. In this direction different systems including synthesized or natural ones have been studied. One of the advantages of the synthesized material is to control the composition, and so, the impurity of the starting materials used to prepare the solid state dosimeters. On the other hand, natural minerals are available in reasonably large quantities as well as at low expenses and found to play an important role in Archeology and Geology as some of these are found to have good potential for both dosimetric and TL dating materials $[1,2]$. Materials which show good TL response

\footnotetext{
* Corresponding author. Tel.: +91 09448116281/080 57659674; fax: +91 8023219295.

E-mail address: bnlnarasappa@rediffmail.com (B.N. Lakshminarasappa).
}

for low amount of radiations (dose from $\sim 10^{-5} \mathrm{~Gy}$ to a few hundred Gys before reaching saturation) are found to be the best materials for TL dosimetric applications.

Estimation of the amount of doses absorbed by a particular material from different dosimetric techniques is highly informative [3]. However, such data has not yet been reported using a single solid state TL dosimeter. The TL response of dosimetric materials exposed to energetic heavy charged particles can be viewed as a tool to investigate mechanism of ion interaction with matter and subsequently for the TL process. From a practical point of view, the knowledge of the TL response as a function of dose, type of ion particle and its energy etc could permit us for selecting materials as TL dosimeters for heavy ion charged particle irradiation [4].

In this paper, we report the TL behavior of natural kyanite subjected to swift heavy ions $-\mathrm{Si}^{8+}$ and $\mathrm{Ag}^{8+}$. Natural kyanite, a crystalline aluminum silicate $\left(\mathrm{Al}_{2} \mathrm{SiO}_{5}\right)$ is one of the silicate groups of mineral, used in the production of non-fusion cast tank blocks, in the manufacture of spark 
plugs and as mineral specimens. It is a polymorph with three other minerals - andulasite, sillimanite and mullite. Kyanite, a triclinic occurs in long thin blade like form usually transparent to translucent, color in blue, white or brown also gray or green and rarely black or streak $[5]$.

\section{Experimental}

Crystals of kyanite of $\sim 1 \mathrm{~mm}$ thickness and $\sim 60 \mathrm{~mm}^{2}$ areas are obtained by cleaving long thin block of natural kyanite procured from Geology Department, Bangalore University. Irradiation with $100 \mathrm{MeV} \mathrm{Si}{ }^{8+}$ and $\mathrm{Ag}^{8+}$ ions for doses in the range of $1 \times 10^{11}-1 \times 10^{14} \mathrm{ions} / \mathrm{cm}^{2}$ was done at 15UD Pelletron facility, Nuclear Science Centre, New Delhi. The detailed experimental set up for ion irradiation was described elsewhere [6]. After heavy ion irradiation, the samples were subjected for thermoluminescence measurements using an home made TL set up [7] consisting of RCA 931A photomultiplier tube and a digiscribe 5000 series strip chart recorder by heating the sample at a constant rate of $20 \mathrm{~K} \mathrm{~min}^{-1}$. The temperature of the sample along with intensity of light emitted were simultaneously recorded.

\section{Results and discussion}

The values of TL intensity and the corresponding temperature were calculated from the experimentally recorded glow curves and redrawn to actual scale. The TL glow curves of kyanite single crystals bombarded with $100 \mathrm{MeV}$ swift $\mathrm{Si}^{8+}$ ions with fluences in the range $1 \times$ $10^{11}-5 \times 10^{13}$ ions $/ \mathrm{cm}^{2}$ are shown in Fig. 1. Two glow peaks a weakly resolved one at $\sim 445 \mathrm{~K}$ and a well resolved

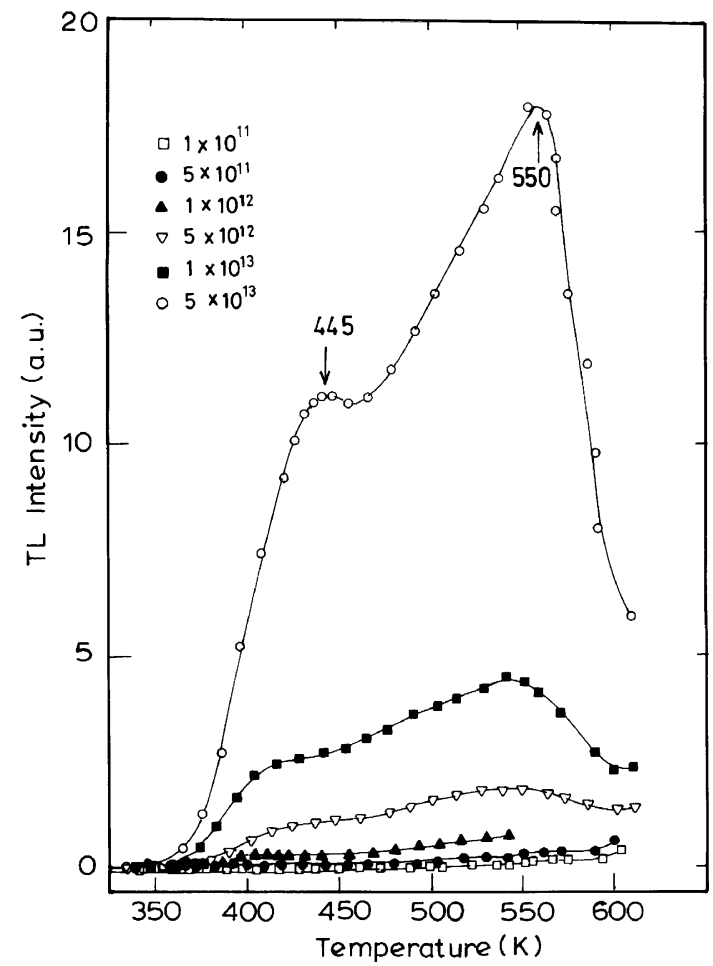

Fig. 1. Thermoluminescence glow curves in $100 \mathrm{MeV} \mathrm{Si}^{8+}$ ion irradiated kyanite single crystals.

glow with peak at $\sim 550 \mathrm{~K}$ are observed. It is found that the TL intensity at these glow peaks increase linearly with increase of $\mathrm{Si}^{8+}$ ion dose and this might be due to the creation of new traps with ion bombardment processes [8].

In the case of $\mathrm{Ag}^{8+}$ ions, a single well resolved glow with peak at $\sim 520 \mathrm{~K}$ was observed in all kyanite crystals bombarded with fluences in the range $1 \times 10^{11}-5 \times$

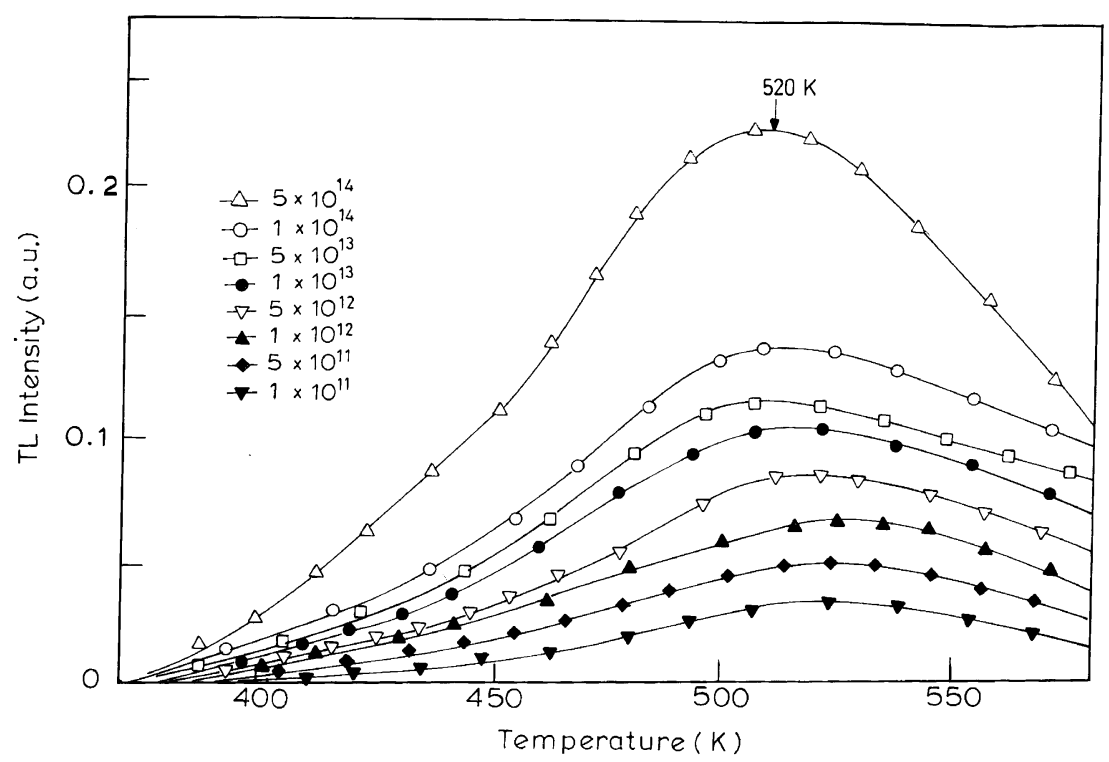

Fig. 2. Thermoluminescence glow curves in $100 \mathrm{MeV} \mathrm{Ag}^{8+}$ ion irradiated kyanite single crystals. 


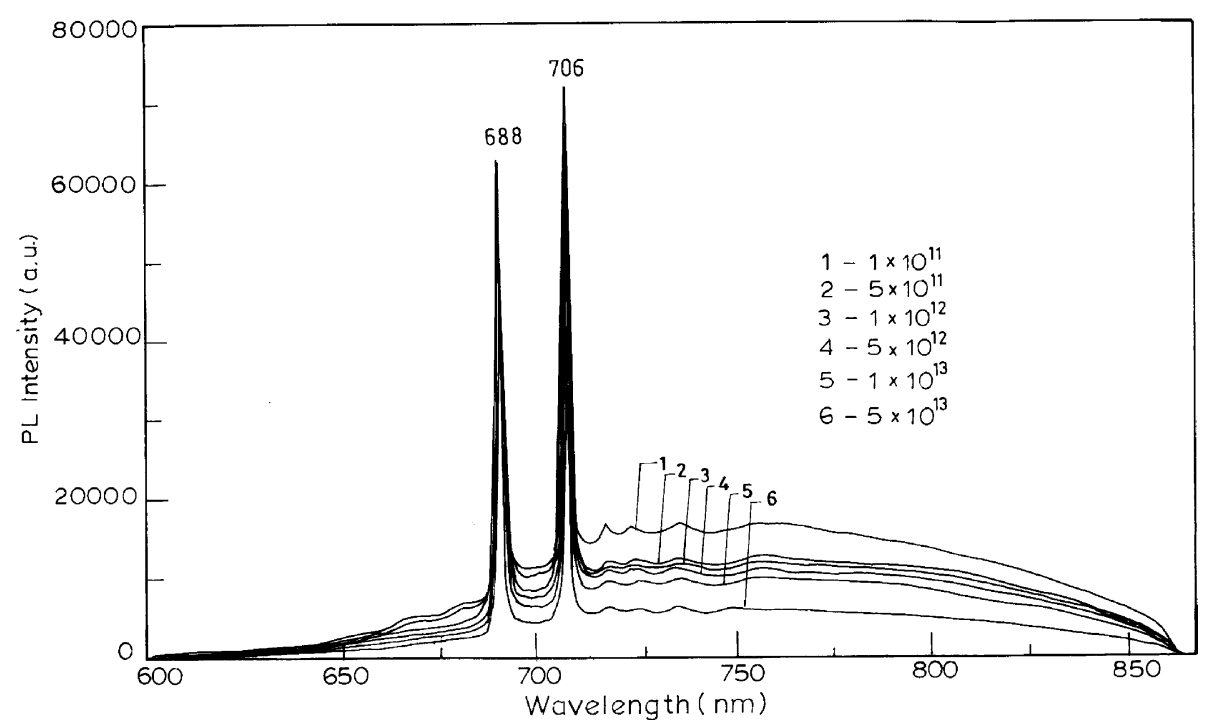

Fig. 3. Photoluminescence spectra $\left(\lambda_{\text {excitation }} 442 \mathrm{~nm}\right)$ of $100 \mathrm{MeV} \mathrm{Ag}^{8+}$ ion irradiated kyanite single crystals.

$10^{14}$ ions $/ \mathrm{cm}^{2}$ as shown in Fig. 2. The glow peak intensity is found to increase with increase of $\mathrm{Ag}^{8+}$ ions as has been observed in $\mathrm{Si}^{8+}$ ion bombarded kyanite. Higher fluences of $\mathrm{Si}^{8+}$ and $\mathrm{Ag}^{8+}$ ions probably lead to generation of higher concentration of defect centers in kyanite. And, further fluence may results in destruction of defect centers leading to amorphization of the material.

The TL intensity, for a given dose, is found to be enhanced in $\mathrm{Si}^{8+}$ ion irradiated samples when compared to $\mathrm{Ag}^{8+}$ ions irradiated samples. This might be due to quenching of luminescence through the interaction of defects produced by $\mathrm{Ag}^{8+}$ ions. It is found that, the $\mathrm{TL}$ glow peaks in swift heavy ion irradiated kyanite single crystals are not well resolved when compared to TL glow peaks observed in $\gamma$ - and $\beta$-irradiated kyanite crystals [6]. This may be attributed to nature and size of the ion species.

Photoluminescence spectra of kyanite single crystals bombarded with $100 \mathrm{MeV} \mathrm{Ag}^{8+}$ ions for fluences ranging from $1 \times 10^{11}-5 \times 10^{13}$ ions $/ \mathrm{cm}^{2}$ followed by excitation with $442 \mathrm{~nm}$ laser beam have been studied and the results are shown in Fig. 3. A pair of sharp and strong emission bands with peaks at $\sim 688$ and $706 \mathrm{~nm}$ and a broad emission band in the region $710-800 \mathrm{~nm}$ are observed. The sharp emission observed with peaks at 688 and $706 \mathrm{~nm}$ may be attributed to luminescence centers activated by $\mathrm{Fe}^{3+}$ ions which are detected from EDXA experiment [6]. The characteristics of the center giving rise to sharp emission is within the $4 \mathrm{f}$ shell, which is partially shielded by the most outer electrons $3 \mathrm{~S}^{2} 3 \mathrm{P}^{6}[9]$. The shape and the full width at half maximum of the bands in the luminescence spectrum depend on temperature and the strength of the interaction between the electrons and phonons, which participate in the optical transition. At low temperature, the luminescence spectra consist of sharp peaks and narrow bands. Strong electron phonon interactions results in broadening of the peaks in the spectra. Extrinsic luminescence depends on the impurities in the crystal through the process of activation, sensitization and quenching $[9,10]$.

\section{Conclusions}

The TL glow peak intensity increases linearly with increase of $\mathrm{Si}^{8+}$ ion dose. This is attributed to creation of new traps with bombardment process. The decrease of PL intensities with increase of $\mathrm{Ag}^{8+}$ ion fluence might be attributed to amorphization. Sharp emission peaks at 688 and $706 \mathrm{~nm}$ with $442 \mathrm{~nm}$ laser excited beam may be attributed to $\mathrm{Fe}^{3+}$ ions. TL glow peaks are not well resolved in ion irradiated samples when compared to $\gamma$ - and $\beta$-irradiated samples. This might be attributed to nature of ionizing radiation.

\section{Acknowledgements}

The authors wish to express their thanks to Dr. D.K. Avasthi, Nuclear Science Centre (NSC), New Delhi, for useful discussion, besides his constant help and encouragement in this work. One of the authors (H.N.) thanks NSC for the award of fellowship under UFUP scheme.

\section{References}

[1] J.M. Luthra, in: K.V.R. Murthy, L.H.H. Prasad, T.R. Joshi (Eds.), Thermoluminescence and its Applications, Tata McGraw Hill Publishing Co. Ltd., New Delhi, 1992, p. 122.

[2] D.N. Souza, M.E.G. Valerio, J.F. Delima, L.V.E. Caldas, Nucl. Instr. and Meth. B 167 (2000) 214.

[3] Y.H. Horowitz, Thermoluminescence and Thermoluminescent dosimetry, CRC Press, USA (FL), 1994.

[4] Gamboa-debuen, C. Ruitz, A. Oliver, L. Lopez, M.E. Brandan, Nucl. Instr. and Meth. B 134 (1998) 148.

[5] H.H. Read, Rutleys Elements of Mineralogy, Thomas Murphy, 1953, p. 548.

[6] H. Nagabhushana, Ph.D. Thesis, Bangalore University, Bangalore 2002. 
[7] B.N. Lakshminarasappa, Ph.D. Thesis, Bangalore University, Bangalore 1990, p. 64.

[8] H.M. Abdel-Hamid, H.M. Saad, S.M. Morsy, M.A. Hussein, Nucl. Instr. and Meth. B 129 (1997) 73.
[9] H. Nagabhushana, B.N. Lakshminarasappa, Fouran Singh, D.K. Avasthi, Radiat. Meas. 36 (2003) 643

[10] C.G Ryan, D.R. Cousens, S.H. Sie, W.L. Griffin, Nucl. Instr. and Meth. B 49 (1990) 271. 